\title{
Trifluoroacetic Acid (TFA)
}

\section{Matthew D. Norris}

School of Chemical and Physical Sciences, Flinders University, GPO Box 2100, SA 5001, Adelaide, Australia

matthew.norris@flinders.edu.au

Published online: 23.01 .2015

DOI: 10.1055/s-0034-1379995; Art ID: st-2014-v0507-v
Matthew D. Norris was born in Bedford Park South Australia and studied organic chemistry at Flinders University, receiving his B.Sc. (Hons) in 2011. He was then awarded the MF \& MH Joyner Scholarship in Science and began doctoral work as a student of Associate Professor Michael V. Perkins. Matthew also received the Australian Fulbright Alumni (WG Walker) Postgraduate Scholarship and worked with Professor Erik J. Sorensen at Princeton University in 2014. His research has focused on chemical synthesis and methodology with a strong emphasis on the total synthesis of natural products.

The trifluoroacetyl group has unique chemical properties that can facilitate a wide variety of transformations often with greater efficiency, selectivity and atom economy than methods otherwise developed. It can act as an effective acid catalyst, activate substrates to chemical fragmentation and multi-bond forming processes and complement transition-metal catalysis as a suitable counterion. ${ }^{1}$ Importantly, TFA is cheap and readily available; non-toxic; resistant to photochemical and environmental degradation, metabolism in plants, animals and microorganisms; is highly soluble in organic and aqueous solvents and is easily removed from chemical processes as the non-hazardous acetate salt. ${ }^{2}$ TFA is prepared industrially by the electrofluorination of acetyl chloride or acetic anhydride in anhydrous hydrofluoric acid, followed by hydrolysis of the resulting acid fluoride. ${ }^{1}$

Table 1 Use of Trifluoroacetic Acid (TFA)

(A) Installation and removal of protecting groups:

TFA is widely used for the installation and removal of protecting groups by acidic condensation and hydrolysis, respectively. ${ }^{1}$ It is commonly employed for the condensation of mono- and di-alcohols with trichloroacetimidates, carbonyls and acetals to yield ether and acetal protecting groups. It is also used for the catalytic or stoichiometric removal of acetals, benzyl ethers, silyl ethers, tert-butoxycarbonate esters and tert-butyl ethers and esters. TFA is often applied in the final stages of solid-phase peptide synthesis for the global removal of protecting groups and scission of peptide substrates from solid supports. ${ }^{3}$ This can also activate and encourage folding of the secondary and tertiary peptide structure. The trifluoroacetate ester itself can be installed as a non-enolisable acetyl protecting group for alcohols, amines and thiols. ${ }^{4}$ It is typically introduced by the condensation of trifluoroacetic anhydride (TFAA) or ethyl trifluoroacetate and removed by base hydrolysis or transesterification.<smiles>CCCCC(NC(=O)C(Cc1ccc(OC(C)(C)C)cc1)NC(C)=O)C(=O)NC(C(=O)NC(CC(C)C)C(=O)NCC(=O)O)C(=O)NC(CC(C)C)C(=O)NCC(=O)O</smiles> 
(B) Cyclisation reactions and multi-bond forming processes:

A high level of acidity and solubility in both organic and aqueous solvents makes TFA an ideal reagent to activate polarised functional groups and promote the generation of organic cations in solution, which can encourage cyclisation reactions, rearrangements and multi-bond forming processes. One of the most notable examples of this is the acid-catalysed $\pi$-cation cyclisation of polyenes in the synthesis of steroid ring systems. ${ }^{5}$ More recently, a total synthesis of the non-opioid analgesic conolidine was realised in a tandem imine condensation and intramolecular Mannich reaction catalysed by TFA. ${ }^{6}$ In another example, the unsaturated furanylidene core structure of the polyketide metabolites gracilioether $\mathrm{B}, \mathrm{C}$ and spongosoritin A was constructed in a biomimetic cyclisation-dehydration cascade. $^{7}$
(C) Dehydrating agent:

Due to the stability and non-nucleophilic character of trifluoroacetate, elimination of $\beta$-hydroxy carbonyls to $\alpha, \beta$-unsaturated systems is easily effected with TFAA under mildly basic or neutral conditions. Whitehead ${ }^{8}$ was able to access derivatives of the manzamenone polyketide metabolites in a biomimetic dehydrative dimerisation of $( \pm)$-untenone $A$ by the addition of TFAA followed by a range of external nucleophiles.

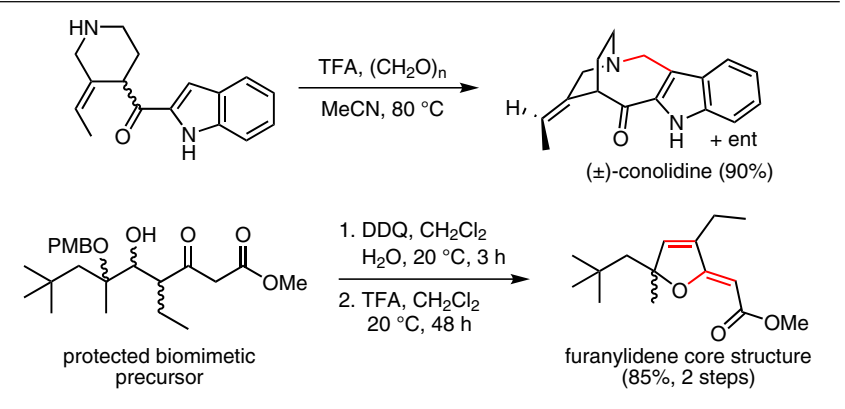

(D) Fragmentation:

Detrifluoroacetylative fragmentation, similar to the decarboxylation of $\beta$-keto acids, facilitates the formation of fluorinated enolate nucleophiles, which can participate in aldol reactions and $\alpha$-halogenation under exceptionally mild conditions. ${ }^{9}$ Aldol reactions assisted by pendant trifluoroacetate groups have also been developed to effect olefination yielding $\alpha, \beta$-unsaturated carbonyl systems. ${ }^{10}$

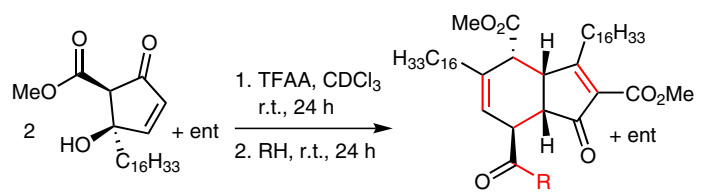

( \pm -)-untenone A

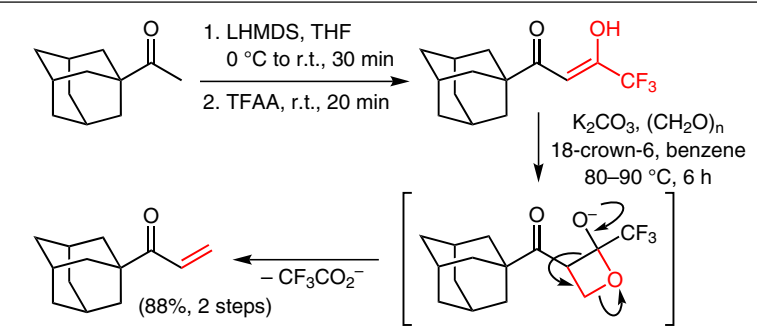

(E) Transition-metal catalysis and oxidation reactions:

Trifluoroacetate is used extensively as a counterion in transitionmetal catalysis and is often used for stoichiometric activation of DMSO in Swern-Moffat oxidations. Recently, palladium(II) trifluoroacetate effected a Wacker-Heck cascade to establish the chroman framework of vitamin $\mathrm{E} ;{ }^{11}$ an effective procedure for the oxidative coupling of indoles with thallium(III) trifluoroacetate was developed; ${ }^{12}$ and a novel DMSO-mediated oxidation of isonitriles to isocyanates was demonstrated with catalytic TFAA. ${ }^{13}$

\section{References and Notes}

(1) For a recent and comprehensive review on synthetic applications of TFA, see: López, S. E.; Salazar, J. J. Fluorine Chem. 2013, $156,73$.

(2) Han, C.; Kim, E. H.; Colby, D. A. Synlett 2012, 23, 1559.

(3) Eberhard, H.; Seitz, O. Org. Biol. Chem. 2008, 6, 1349.

(4) López, S. E.; Restrepo, J.; Salazar, J. Curr. Org. Synth. 2010, 7, 414.

(5) (a) Johnson, W. S.; Semmelhack, M. F.; Sultanbawa, M. U. S.; Dolak, L. A. J. Am. Chem. Soc. 1968, 90, 2994. (b) Johnson, W. S.; Gravestock, M. B.; McCarry, B. E. J. Am. Chem. Soc. 1971, 93, 4332.

(6) Tarselli, M. A.; Raehal, K. M.; Brasher, A. K.; Streicher, J. M.; Groer, C. E.; Cameron, M. D.; Bohn, L. M.; Micalizio, G. C. Nat. Chem. 2011, 3, 449 .
(7) Norris, M. D.; Perkins, M. V. Tetrahedron 2013, 69, 9813

(8) Doncaster, J. R.; Etchells, L. L.; Kershaw, N. M.; Nakamura, R.; Ryan, H.; Takeuchi, R.; Sakaguchi, K.; Sardarian, A.; Whitehead, R. C. Bioorg. Med. Chem. Lett. 2006, 16, 2877.

(9) (a) Han, C.; Kim, E. H.; Colby, D. A. J. Am. Chem. Soc. 2011, 133, 5802. (b) John, J. P.; Colby, D. A. J. Org. Chem. 2011, 76, 9163.

(10) Riofski, M. V.; John, J. P.; Zheng, M. M.; Kirshner, J.; Colby, D. A. J. Org. Chem. 2011, 76, 3676

(11) Tietze, L. F.; Stecker, F.; Zinngrebe, J.; Sommer, K. M. Chem. Eur. J. 2006, 12,8770 .

(12) Keller, P. A.; Yepuri, N. R.; Kelso, M. J.; Mariani, M.; Skelton, B. W.; White, A. H. Tetrahedron 2008, 64, 7787.

(13) Le, H. V.; Ganem, B. Org. Lett. 2011, 13, 2584 